\title{
A escrita política e o pensamento dos Guarani em tempos de autogoverno (c.1753)
}

\author{
The political writing and the Guarani \\ thinking in times of self-government (c.1753)
}

Eduardo Santos Neumann*

Capucine Boidin ${ }^{* *}$

\section{Resumo}

Em meados do século XVIII os Guarani das reduções escreveram com frequência, documentos em que expressam um pensamento político próprio. Nesses textos é possível observar sua capacidade de agir, mas também sua percepção dos acontecimentos em curso por meio de um pensamento em guarani. Essa autonomia indígena, em um momento de contestação política, estava embasada nas teorias que pautaram a sua instrução e que paradoxalmente serviram para justificar ações em defesa dos seus interesses, devidamente amparados nos valores da monarquia católica.

Palavras-chave: escrita indígena; Reduções Guaranis; pensamento político.

\section{Abstract}

By the middle of eighteen century, the Guarani from the reductions frequently wrote their own documents in which were expressed their very political thoughts. Through these texts it is possible to observe not only their action capacity but also their perception of the events in progress by a Guarani way of thinking. This indigenous autonomy, in a moment of political contestation, was based upon the theories which they were taught and which paradoxically served to justify their actions on defending their interests, properly supported on the catholic monarchy values.

Keywords: Indigenous writing; Guarani Reductions; political thought.

Os historiadores vêm dedicando atenção crescente aos textos redigidos pelos indígenas em línguas ameríndias, documentos analisados com base em um diálogo com a antropologia. ${ }^{1}$ A valorização dessas fontes, testemunhos singulares dessa época, despertou nos últimos anos a atenção dos

\footnotetext{
* Programa de Pós-Graduação em História, Universidade Federal do Rio Grande do Sul (PPGHIS/ UFRGS). Porto Alegre, RS, Brasil. eduardosneumann@gmail.com

** Université Sorbonne Nouvelle Paris 3 - Institut des Hautes Études d'Amerique Latine (IHEALINALCO). Paris, France. capucine.boidin@gmail.com
} 
pesquisadores interessados na história das reduções guaranis do Paraguai. ${ }^{2}$ Nesses documentos com "letra de índios" podemos observar uma concepção dos eventos (do passado) narrados pela ótica dos Guarani, mas conhecemos pouco das implicações da escrita política e dos pensamentos expressos em língua indígena (Neumann, 2015).

Durante um período de conflito agudo nas reduções, em meados do século XVIII, os Guarani escreveram intensamente, e os documentos produzidos por eles permitem repensar as relações estabelecidas com o território missioneiro e, especialmente, suas formas de ação política. Esse conjunto de documentos indica uma discussão pouco referida pela historiografia dedicada ao tema, ou seja, a existência da defesa por escrito de um direito a resistir a uma ordem real injusta dos Guarani em redução. Esses textos em língua guarani, e mesmo suas traduções, podem ser novamente analisados tanto pelos aportes da história da cultura escrita como pelos da história dos conceitos políticos. ${ }^{3}$

A expressiva produção de documentos dos índios dessas reduções decorre da assinatura do Tratado de Madri em 1750, entre as monarquias ibéricas, o qual estabelecia a troca da Colônia do Sacramento, de domínio português, na margem setentrional do rio da Prata, por sete reduções localizadas na margem oriental do rio Uruguai. A disputa pelas fronteiras na América do Sul, resultado da rivalidade entre as duas monarquias ibéricas, esteve caracterizada por uma ativa participação dos agentes locais. ${ }^{4}$ Diante das implicações dessa permuta, a elite indígena procurou estabelecer negociações que lhe garantissem o controle das terras orientais.

Assim, o "ponto de vista indígena" a que nos referimos não deve ser entendido apenas no sentido de um comportamento padrão, abrangente, que recaiu sobre toda a população missioneira, perspectiva esta que transformaria os Guarani em um coletivo homogêneo. ${ }^{5}$ É uma maneira de nos referirmos a um determinado momento de enfrentamento em que uma elite letrada se coloca ora como porta-voz, ora como responsável por uma versão escrita dessa coletividade. Não podemos pressupor que essa competência alfabética determinasse um distanciamento dos demais indígenas, mas uma mediação diferenciada com as hierarquias da sociedade e as suas interações possíveis.

Quanto aos manuscritos escritos pelos Guarani rebelados, estavam esquecidos em alguns arquivos e bibliotecas de diferentes países, ${ }^{6}$ motivo pelo qual é importante interpretá-los no contexto de sua produção. Esse desafio nos remete às dificuldades da análise histórica e à hermenêutica de suas próprias condições de escrita. ${ }^{7}$ Nesses textos, os índios recordam constantemente às autoridades reais todo o empenho da população missioneira em assegurar esses 
domínios ao monarca de Espanha, recordando a ação indígena nas fronteiras americanas, mas também uma capacidade de argumentar em guarani pautada em conceitos da teoria política neoescolástica. Recorriam ao direito natural e a uma interpretação contratual do pacto monárquico, ou seja, da relação de vassalagem que os vinculava ao rei por sua condição de sujeitos cristãos, justificando dessa maneira o seu direito de não acatar a ordem de mudança (Quarleri, 2009, p.195-200).

Diante da contrariedade por parte da população das reduções orientais à ordem de transmigração estipulada pelo Tratado de Madri e o posterior desacato às determinações dos jesuítas, ocorre um estremecimento das relações entre indígenas e missionários. Apesar dos esforços empreendidos desde 1752, no sentido de colocar em prática a mudança desses Guarani (aproximadamente 30 mil), não foi possível convencê-los a executar a nova medida. No ano seguinte, com a chegada dos comissários demarcadores enviados pelas monarquias ibéricas ao território implicado nessa permuta, inicia-se um longo período de polêmicas e controvérsias na América meridional.

\section{O PROTAGONISMO INDÍGENA E AS COMISSÕES DEMARCADORAS}

A tentativa de definir a fronteira meridional detonou a suspeita sobre o envolvimento dos jesuítas (ou de alguns deles) acusados de responsáveis por incitarem os Guarani das reduções à rebelião. Essa controvérsia sempre ocupou lugar central no debate historiográfico sobre a "guerra guaranítica", em que se atribuiu aos jesuítas grande influência no desfecho desses acontecimentos, minimizado o poder de decisão dos indígenas. Entretanto, o principal óbice à execução da demarcação dos novos limites foi a negativa indígena de abandonar as reduções. De fato, essa oposição rapidamente transformou-se em uma rebelião que, apesar de não ter sido estimulada abertamente pelos jesuítas missioneiros, estes quase nada puderam fazer para impedi-la.

Atualmente, a perspectiva que se tem adotado ao interpretar o passado missioneiro é a de conceber maior centralidade aos indígenas na organização social, nas atividades cotidianas e nos rumos dos conflitos na região. Segundo Guillermo Wilde (2003, p.28) o liderazgo indígena apresentou grande relevância na organização interna, pois "conservó autonomía a los cacicazgos que se integraron a las reducciones, desarrollo un lenguaje político que permitió imaginar la nueva comunidad y estandarizó el ritual y la guerra como prácticas aglutinantes de la población indígena”. Essa autonomia dos “cacicazgos" é ainda mais visível com a crise geopolítica criada pelo tratado de Madri. 
Sabemos que a chegada das primeiras equipes de funcionários encarregados da demarcação de limites na América meridional gerou manifestações de hostilidade dos índios à presença dessas autoridades. ${ }^{8}$ Os episódios relacionados à definição dos novos limites determinaram outra correlação de forças no interior das reduções orientais. A autoridade dos jesuítas foi rapidamente confrontada pelas lideranças indígenas.

O poder temporal dos jesuítas, já contestado em outros momentos, foi desconsiderado por uma parcela da população contrária à aplicação das cláusulas presentes ao Tratado de Limites. Nas reduções, o relacionamento entre os missionários e as lideranças guaranis foi de constante negociação (Avellaneda, 1999). Por vezes, os índios demonstraram interesse em arbitrar nos temas relativos ao "governo político", conflitando com a autoridade dos padres.

A documentação de circulação interna, de caráter reservado, enviada pelos jesuítas missioneiros aos seus superiores, permite acompanhar o papel desempenhado por determinadas lideranças durante o período de demarcação. Muitos Guarani, por sua condição de elite indígena, estavam exercendo atividades administrativas e assumem posições de destaque nesse momento de redefinição dos espaços coloniais. A leitura e o cruzamento das informações históricas têm revelado a presença de distintos indígenas envolvidos nesse alvoroto missioneiro. Alguns nomes como Alexandro Mbaruari, Cristoval Paica, Rafael Paracatu, Miguel Mayra, Pasqual Yaguapo, Primo Ybarenda, Hilário Yrama e Valentin Ybarigua, entre outros, não eram considerados na historiografia como sujeitos dignos de menção. ${ }^{9}$

No período de demarcação houve a preocupação, principalmente dos jesuítas, em registrar certos traços de caráter individual de alguns indivíduos, além das referências genéricas com as quais costumavam descrever seus fiéis. Dada a atuação desses índios principais, há nas fontes históricas a descrição de características mais particulares, visto que, em alguns momentos, foi necessário denunciar ou mesmo alertar quanto ao possível grau de "periculosidade" de alguns insurretos.

Assim, em janeiro de 1753, Lorenzo Balda, em carta ao comissário Lope Luiz Altamirano - plenipotenciário da Companhia de Jesus nos trabalhos de demarcação -, informou a respeito da ação de alguns indígenas. Segundo esse jesuíta, três deles já deviam ter sido desterrados: "Pedro Payca, Miguel Mayra, Agustin Mayra que se hace cacique sin serlo. Estos han pervertido a los caciques siguientes, Alexandro Guaytipoi, que tiene 9 vasallos. Clemente Tariuma, 
que tiene 89. Bernabé Payare que tiene 53. Mariano Payca 44. Feray 106. Yarui 82 y otros que handan a sombra detexado". ${ }^{10}$

É evidente na mensagem a importância dos caciques, explicitada diante da informação do número de vassalos que cada um comandava. Nesse contexto de crise novas lideranças estavam se destacando e angariando prestígio, além daquelas autorizadas pelos jesuítas. Como se pode observar nos informes de alguns missionários, surgem nomes e sobrenomes dos principais Guarani rebelados. Frente a esse protesto generalizado o proprio Balda recomendava, nessa carta, que "a los tres primeros después de bien sobados los destierre, adonde nunca se vean y a los otros que se buelvan después de bien sobados, y tambien si fuere entre ellos uno llamado Felipe Zubai, que es gran revolvedor que sea desterrado por algun tiempo".

A sugestão de medidas dessa natureza é uma prova do quanto os índios que ocupavam os cargos nos cabildos missioneiros - modalidade de conselho municipal - estavam agindo por motivação própria, como agentes políticos autônomos e, sobretudo, em oposição frontal às orientações dos jesuítas. Manifestações dessa natureza indicam não ter havido passividade guarani e que tampouco eles foram manipulados pelos jesuítas: as atitudes estiveram motivadas por lógicas próprias, resultado da interação de autoridades nativas com a sociedade colonial (Wilde, 2009). Graças à carta de Lorenzo Balda sabemos que Felipe Zubay, secretário de São Miguel, com Sepé Tiarayú e o alcaide maior dessa redução, manteve contato com a primeira partida demarcadora, em fevereiro de 1753. Nesses encontros, os secretários foram figuras-chaves por suas habilidades letradas e, provavelmente, por apresentarem algum conhecimento do idioma espanhol. Igualmente, sempre estiveram presentes em situações solenes, em momentos de tomada de decisão para os rumos da vida em redução. Afinal, eles eram os sujeitos responsáveis pela memória escrita e, portanto, indivíduos capazes de atuar de maneira próxima à lógica ocidental. Outros secretários também participaram em momentos de contato com os demarcadores, demonstrando as relações existentes entre escrita e poder nos cabildos missioneiros.

Entre os líderes indígenas que se destacaram nesse período, foram os caciques os principais responsáveis pela oposição à ordem de mudança, e diversos episódios ocorreram nas reduções orientais diante da cizânia entre eles e os corregedores, que se posicionaram, inicialmente, de maneira favorável à mudança, em desacordo frontal com a decisão dos caciques e demais integrantes dos cabildos. O padre Luis Charlet, responsável pela redução de São Lourenço, em carta a Altamirano datada de 27 de março de 1753, expressava 
com clareza essa nova realidade: "Los caciques sin que lo sepamos, si(n) hacer caso de nosotros, envían su gente, se avisan con sus papeles de día, y de noche, y dicen que si los españoles vienen a ayudar los portugueses que irán, que harán...”."11

Por sua vez, a tentativa empreendida pelos jesuítas no sentido de cooptar os corregedores - conhecidos por serem homens de confiança dos missionários e desempenharem o papel de mediadores entre a massa indígena e os religiosos - resultou em reações violentas por parte dos caciques. Alguns corregedores correram risco de morte ou foram afastados das suas funções porque procuravam convencer os demais da necessidade da transmigração. ${ }^{12}$ E o padre Luis Charlet, ao tentar novamente convencer um cacique a respeito da ordem de mudança, por exemplo, recebeu esta resposta: "dexate desto padre, y no nos moleste mas sobre ello". ${ }^{13}$

\section{Autonomia e Autogoverno}

Assim que foram confirmadas as ordens de mudança, os Guarani colocaram em prática seu autogoverno nas reduções. $\mathrm{O}$ estremecimento das relações com os jesuítas determinou o uso frequente da comunicação escrita que atendia à necessidade de diligência no repasse das informações. Por sua vez, os indígenas que ainda se mantinham receptivos aos jesuítas foram comunicados por escrito do risco que estavam correndo. O padre Luis Charlet, em 1753, mencionou um papel interceptado cuja mensagem advertia os poucos Guarani que seguiam apoiando os jesuítas: "Hemos sabido que vosotros contra nuestra voluntad estáis obedeciendo al padre por tanto queremos ir allá; pero antes que lleguemos tratad de irnos con el padre a donde quisierdes, porque si os hallamos morrireis todos à nuestras manos". ${ }^{14}$

Por meio desse bilhete, verificamos a manifestação da autonomia de um grupo de indígenas frente ao poder que anteriormente era prerrogativa exclusiva dos missionários. Mesmo contando com algum apoio, os religiosos estavam com sua capacidade de convencimento debilitada diante do autogoverno guarani. A partir desse momento os integrantes dos cabildos missioneiros começaram a trabalhar no sentido de congregar a população missioneira em torno de uma postura comum. A escrita foi um instrumento político acionado para a mobilização indígena e sinaliza a deterioração da relação com as autoridades e, principalmente, a perda de confiança nos jesuítas encarregados de administrar as reduções. A carta do missionário Lorenzo Balda ao comissário Lope Luiz Altamirano, escrita em São Miguel no dia 19 de janeiro de 1753, 
evidencia essa tensão: "Dieronme palabra que no se haria daño pero que se les quitase el Corregidor y que nadie les tocase mas punto de mudanza; y volviendose a mi me dixeron que les mandasse cuanto yo quisiese, que me odebezerian, pero que jamás le tocase dicho punto". ${ }^{15}$

Sabemos que a desconfiança dos Guarani em relação aos missionários agravou-se diante da insistência de alguns destes em defenderem a necessidade da transmigração, despertando a suspeita quanto ao interesse dos jesuítas na execução do tratado. Nesse contexto de enfrentamentos novas lideranças haviam angariado evidência, sendo reconhecidos pelos demais indígenas, mas desconsiderados como tal pelos jesuítas. Para coibir a ação dos insubmissos e evitar uma propagação do alvoroto, os jesuítas procederam ao desterro de alguns indígenas. Contudo, a adoção de tais medidas não apresentou resultados positivos, e a insubordinação alastrou-se a outras reduções, inclusive àquelas que não estavam envolvidas diretamente na permuta. A tentativa dos jesuítas de solucionar a negativa indígena com os métodos já conhecidos, como eram os desterros, esbarrou na posição decidida dos índios principais, que se negavam a aceitar qualquer tipo de argumento, mesmo quando mediados por suas lideranças.

Quem ganhou destaque na condução da milícia indígena foi José Ventura Tiarayu. Ele era conhecido pela alcunha de Sepé Tiarayu. Dispomos de algumas informações a respeito da sua trajetória, principalmente a partir da sua captura e posterior fuga do fortim português, nas imediações do rio Pardo. Sabemos que era natural de São Luiz Gonzaga, mas os registros que mencionam sua ação correspondem ao período em que já ocupava o cargo de alferez (tenente) na redução de São Miguel. E a documentação indica que ele era alfabetizado e sabia expressar-se minimamente em língua castelhana. Segundo a informação de Thadeo Henis, Sepé "sabia pronunciar algunas voces de la lengua española”. Exatamente por sua trajetória, ele angariou autoridade e prestígio e foi alçado à condição de liderança. Há muitas obras dedicadas a Sepé Tiarayu, mas poucas pesquisas com bom embasamento histórico.

As referências a ele nas fontes se estendem de 1753 a 1756, ano de sua morte. Durante aproximadamente 3 anos Sepé é mencionado com frequência na documentação. Em certa ocasião, ele tentou acalmar os Guarani mais exaltados, solicitando que permitissem a saída dos padres que mantinham incomunicáveis na estância onde estavam aquartelados. Porém, mesmo no intuito de auxiliar os jesuítas, Sepé cobra uma atitude dos jesuítas, dizendo que os padres "son los que tienen y enseñan las buenas costumbres: Mirad que no los 
perdaís dejandolos irse de con vosotros, ni vosotros los deseéis esto mismo repetio otras tres veces San Miguel al Cacique Don Alonso Tapayu". ${ }^{16}$

Nessa carta, Sepé ainda recordava a aparição de São Miguel, padroeiro da guerra, e cobrava uma atitude coerente dos padres com os ensinamentos que haviam pregado e ensinado aos Guarani. As seguidas tentativas dos jesuítas, no sentido de facilitar aos demarcadores a execução de seus trabalhos, contribuíram para consumar o rompimento da aliança com os índios das reduções que, a partir desse momento, destinaram à escrita uma finalidade política, ou seja, de instrumento primordial de suas práticas de autogoverno, expressando um pensamento político em guarani.

\section{Fevereiro de 1753: A Carta de Mbaruari}

O envio de mensagens escritas sempre foi o meio de comunicação mais eficiente para o gerenciamento das reduções, fazendo parte do cotidiano missioneiro e configurando a espinha dorsal de atuação da Companhia de Jesus. Sem dúvida, o destino conferido pelos Guarani à escrita resulta do convívio dessa elite letrada com os jesuítas. As correspondências escritas pelos índios foram direcionadas aos comissários, aos padres missioneiros e aos demais Guarani rebelados, comprovando o amplo uso de que a palavra escrita desfrutou como instrumento de comunicação estratégica entre a população das reduções.

Nesse contexto, começaram a surgir escritos indígenas em grande quantidade e com frequência pouco usual em relação aos períodos anteriores. No final de fevereiro de 1753, pouco antes do encontro com a primeira comissão demarcadora, o tenente guarani Alexandro Mbaruari, por exemplo, escreveu ao corregedor de São Miguel, Pasqual Tirapare. ${ }^{17}$

Nessa carta, Mbaruari participava ao corregedor da sua redução o conteúdo da correspondência enviada pelo provincial e pelo superior dos jesuítas, assim como pelo governador. Esclarecia que estas se referem às "intenciones de los malos Portugueses" (Portugez vai jesaereko) e à necessidade de manter o ânimo nas reduções e estâncias (toñemomburu katu), sem demonstrar preocupação (porombopy'a e'ỹ), mas sem sair a caçar perto dos portugueses ou pegar animais porque senão eles virão muito rápido (mymba gueropysy ramo kuriteĩhápe ou voine).

Afirma que o provincial, em concordância com o superior e o governador, dizem, em suas cartas (ojávo oñe'êkuatia pype), que "no son regalos de Dios para los Portugueses estas tierras” (na portuges upe tupã remime'ẽngue ruguãi 
evokoi yvy), que "nuestros hijos deben enseñar su fuerza" (ñande ra'y reta ombojekuaa katu ombaraete katu háva) para que os portugueses tenham medo e não cheguem logo (ndoui(che) portuges voíne okyh(y)je ko'yténe). Repetem com insistência as orientações contidas nas cartas: que devem estar preparados em suas reduções (toñemombaraete katu táva rehe) pois assim nada de mal acontecerá (ndoguatáiche teko marã amo).

Nesse texto, os Guarani mencionam ainda que o bom padre Tadeo Henis (Pa'i Tadeo marangatu) os havia aconselhado a se comportarem com humildade e generosidade ante o "padre cura" que lhes visitava (toñemomirĩ Pa'i avare upe), de maneira que "Dios Nuestro Señor" (tupã ñande jára) tenha piedade (peporiahuverekone) e os ajude contra todos os inimigos (pepytyvõne $p(o)$ romoatãre'ỹmba heguíne). Como parte de seus argumentos, recordam ainda um incidente que ocorreu em Montevidéu entre os "infiéis" (ikarai e’ỹ) e os espanhóis e os portugueses conduzidos por seu chefe, o Marquês (Portuges rehe Hae carai rubicha Marques Eha rehe): ocasião em que mataram e roubaram seus animais.

Para finalizar, afirmam que esse fato era a prova de que "Dios nuestro Señor tiene piedad de nosotros" (ñande poriahu vereko). Que convida a ter lástima (poriahu toguereko) e a não empobrecer/enfraquecer (tomomboriahu eme) aos "infieles" quando os escute/ouça. Essa atitude parece ser recomendada pelo bom padre cura (provavelmente é o padre Tadeo Henis).

Estas três condutas - humilde com o padre comissário, forte com os portugueses a compassiva com os infiéis -, ao que tudo indica, foram sugeridas pelo governador, o superior e o provincial dos jesuítas (que escreveu e lhes escreve cartas), e pelo padre Tadeo Henis, que está presente e conversa com eles.

Como podemos interpretar essa carta atualmente? Por acaso essa correspondência seria apenas uma estratégia, um ardil dos indígenas diante da pressão das autoridades religiosas e das políticas coloniais? Pouco provável. Na data em que ela foi escrita duvidamos muito que as autoridades da Companhia de Jesus e o próprio governador de Buenos Aires tenham emitido conselhos com esse teor aos indígenas. É mais provável que estivessem empenhados em convencê-los da ordem de mudança e a obedecerem às decisões dos monarcas. Ou seja: entregar as terras e as reduções orientais aos portugueses. Mas a carta também expressa o esforço e empenho do tenente corregedor para justificar sua própria posição frente às decisões adotadas. Em boa medida buscava um equilíbrio, mesmo que frágil: afinal, como conservar o apoio dos padres e dos índios não reduzidos, e ainda se impor ao inimigo histórico, o português. 
Como se pode constatar, as lideranças indígenas utilizaram a escrita como recurso que visava aumentar as possibilidades de uma ação coordenada contra a iminente chegada dos comissários demarcadores às suas terras. Essa carta visava informar o corregedor de São Miguel sobre a aliança, pouco esperada, estabelecida com as populações indígenas conhecidas como "índios infiéis". Por esse motivo, o tenente Mbaruari tratou de se antecipar aos fatos, procurando assim evitar possíveis constrangimentos com potenciais aliados.

Quando, no final de fevereiro de 1753, concretizou-se o primeiro contato com os comissários demarcadores, os Guarani recorreram à escrita como instrumento de negociação. Após algumas tratativas somente consentiram no avanço dos comissários espanhóis, barrando o caminho aos portugueses. Nesse encontro estavam presentes os já mencionados Joseph Ventura Tiarayu, então alferes de São Miguel, o alcaide maior Miguel Taisuicay e o secretário Felipe Zubay. Os três enviaram uma carta em língua guarani a Echavarría, que logo depois de traduzida foi respondida. ${ }^{18}$

Nessa carta, apresentam as razões pelas quais não abandonam as suas reduções e o motivo pelo qual ainda seguem defendendo-as: "aun con todo eso permitimos, que paséis por esta tierra, que vivimos; pero a los portugueses no concedemos ni un poquito, que pasen por estas tierras ... agregando que ... todos los Caziques se han jurado, y han determinado que no combiene entregarlas". O principal óbice à passagem das comissões demarcadoras, como se pode constatar, era a presença dos portugueses. O discernimento dos índios miguelistas diferenciando o lusitano do espanhol, seja em função dos uniformes seja pelo próprio conhecimento que tinham das línguas ibéricas, demonstra uma percepção aguçada daqueles que realmente eram os inimigos a serem rechaçados.

Desse modo, comunicavam ao comissário Juan Echavarría a decisão de não abandonarem as suas terras. Esse comissário, ao responder a carta dos "três índios", solicitou esclarecimentos quanto aos motivos que alegavam impedir a execução das ordens reais. Echavarría, aliás, solicita na missiva "el favor de su resposta por escrito, que no dudo tenga en su gente quien se la escriba a cuio favor quedare obligado, y prompto a servirlos en quanto sea de su agrado". Com esse pedido, o comissário estimulava o uso da comunicação epistolar, alegando que a medida visava isentá-lo de futuros "cargos que me puede hacer el Rey" diante do não cumprimento da ordem de transmigração. ${ }^{19}$

Por conta dessa solicitação, iniciava uma troca sistemática de mensagens entre os Guarani rebelados, as autoridades reais e os jesuítas, prática que caracterizaria os demais momentos de conflito nas reduções. Em alguns desses 
escritos manifestavam seu entendimento a respeito dos acontecimentos em curso, quando utilizavam um pensamento político elaborado no seu próprio idioma.

\section{JULHO DE 1753: CARTAS GUARANIS AO GOVERNADOR de Buenos Aires. Sua ratio e oratio}

Em maio de 1753, o governador de Buenos Aires, José de Andonaegui, diante da negativa indígena às ordens de transmigração, decidiu enviar por intermédio do superior das missões, Mathias Strobel, uma carta de intimidação aos Guarani rebeldes. Conforme Francisco Mateos (1951, p.246) historiador da Companhia de Jesus, o efeito de tais "cartas fué desastroso en los indios y los confirmó más en su obstinación de no entregar sus pueblos y responder con la guerra a las amenazas de guerra que les hacia el gobernador". Essa conclusão surpreende, principalmente pelo fato de reconhecer que as reações dos indígenas resultaram dos próprios sinais emitidos pelos colonizadores.

Após tomarem conhecimento do conteúdo dessa carta, os índios realizaram suas assembleias e decidiram aceitar a guerra. O provincial José Barreda, em carta ao comissário Valdelirios, escrita em julho de 1753, de Córdoba, reconhecia a falta de autoridade reinante nas reduções: "ya sin respecto a los Padres tumultuados en comun los privan de los oficios, y disponen por si sus expediciones de guerra, embiando fuera del Pueblo tropas, cuando antes de este caso no se atrevia ninguno à salir del Pueblo, sin pedir antes licencia à los padres". ${ }^{20}$

Dessa maneira, os integrantes dos cabildos responderam à ameaça de Andonaegui em julho de 1753, quando foram enviadas sete cartas a Buenos Aires. ${ }^{21}$ Segundo Bartomeu Melià (1997, p.297), essas cartas dos cabildos indígenas são as melhores páginas de literatura guarani, apresentando grande criatividade expressiva "donde aun a partir de conceptos coloniales, de la vida reduccional, se abre paso a un pensamiento guaraní que entronca con los discursos políticos de los jefes religiosos no colonizados". Precisamente, a ratio reporta a uma linguagem política própria da monarquia ibérica em meados do século XVIII, enquanto a oratio se ajusta à arte de persuadir local. Arte verbal no idioma guarani que tanto os padres missioneiros como os caciques e cabildantes valorizavam - transformando-a - dentro das reduções (Boidin, 2016a).

Tais documentos em língua guarani são a expressão maior, mas não única, da articulação política desses indígenas com o império. Há uma insistência, 
por parte de alguns pesquisadores, sobre a excepcionalidade do momento e dessas cartas, mas elas devem ser analisadas como parte de um corpus, um conjunto de documentos mais amplo. ${ }^{22}$ Ao que tudo indica, é a partir de 1752 que os índios exercem com frequência sua arte de persuadir, porém agora por escrito. Nessas ocasiões demonstraram elegância e desenvoltura nos usos dos valores da monarquia católica para justificar interesses próprios.

A comunicação epistolar entre Andonaegui e os cabildantes missioneiros revela outro aspecto do valor conferido à palavra escrita pelos indígenas rebelados, principalmente pelo aparato político-militar que a sustentava. Escrever cartas requer dominar um conjunto de convenções que estava muito além da mera alfabetização. Os Guarani letrados, por compartilharem dos valores culturais subjacentes à escrita, responderam prontamente à carta enviada pelo governador, informando a decisão adotada coletivamente. A comunicação escrita também foi um recurso utilizado por outras populações ameríndias, como nos Andes e no México, para manifestar sua insatisfação com as medidas reformistas adotadas pela monarquia hispânica. ${ }^{23}$

Essas cartas em guarani também são consideradas como um brado autonomista indígena, por apresentarem expressões menos submetidas ao controle ou censura no período reducional. O conteúdo era muito similar, principalmente nos aspectos religiosos e políticos, o que indica a existência de muitas conversas e discussões prévias à sua escrita. Argumentos que, por sua vez, são o resultado das inquietações expostas nas assembleias, oscilando entre uma linguagem de súplica (religiosa) e um tom ameaçador (belicoso). Ainda que as cartas tenham sido remetidas ao governador e exibam conceitos políticos próprios da teoria política neoescolástica, seu público implícito é a população indígena de cada redução e responde aos cânones retóricos ameríndios. Por suas características e estilo as cartas permitem supor que o texto em boa medida é uma transcrição dos discursos orais memorizados, repetidos e comentados ao longo das várias assembleias prévias. Em outras palavras: são textos que procuram atender às normas de persuasão voltadas a dois públicos: os habitantes das reduções e o governador.

A dificuldade em conversar sobre as ordens de mudança, mesmo com os seus próprios subordinados, foi mencionada por Nicolas Ñenguiru. Ele era descendente de uma família de renome, uma linhagem que remonta ao início das reduções, no século XVII. Por sua trajetória, além do respeito e prestígio de que desfrutava, atuava como liderança e manifestou em carta ao governador de Buenos Aires que: "ya no está bien a nosotros hablarles una palabra sobre esta mudanza (imosẽ)". ${ }^{24}$ 
Podemos supor que a palavra que Nicolas Ñeenguiru não pode pronunciar frente à sua gente deve ter sido jakaho, que quer dizer literalmente "despoblar una tierra, mudarse". Pensamos ter sido esse o termo utilizado pelos jesuítas para expressar a ordem expedida pelo rei. Igualmente sabemos que os cabildantes de quatro reduções foram os mais decididos, manifestando de maneira contundente sua opinião contrária à ordem de transmigração: "mudarse (jakaho) no es muy difícil y la guerra también", "este aviso tan difícil y desagradable de mudarnos (jakaho) que nos saca de juicio" (São Luis, s. 5 y 25), "no tenemos donde mudarnos (jakaho)" (São Lorenço, s. 65), "no nos queremos mudar (jakaho)" (São João, s. 41), "ni un tantito hemos cuidado de mudarnos (jakaho)" (São Miguel, s. 42). Porém, na carta escrita pelos cabildantes de São Miguel utilizaram-se outros verbos para dizer que não deixariam as suas terras: syry (deslizar-se de algo, correr de, fugir), po’i (soltar) heja (dejar) (São Miguel, s. 20 e 100). Por sua vez, a carta de São Nicolau e de Concepção (escrita por Nicolas Neenguiru) menciona apenas que o rei e o padre comissário querem $m o$-sẽ "hacer salir". E na carta de São João os seus cabildantes indagavam: "tambien nos quieren echar (oguerova) y apartar (ore pe'a) de esta nuestra tierra?” (São João, s. 38).

Como se pode perceber, há uma sutil guerra de palavras. Pois os jesuítas e o rei ordenaram aos índios "mudarse", mas eles entendem que as ordens são para "hacer salir, sacar, echar, dejar" as suas terras e assim "soltar, dejar, huir de". E a indagação frequente, ao longo dessas cartas, é: "nuestro Rey Santo después que hemos cumplido muy bien sus mandatos, nos quiere sacar de nuestra Tierra (oremosẽ), nos quiere perder (oremokañy) y nos quiere acabar (momba)?" (São Luis, 1753, s. 26).

A carta de São Nicolau, cuja suposta tradução ao espanhol não corresponde ao texto original em guarani, permaneceu até há pouco tempo desconhecida. Redigida em uma das reduções que sempre manifestaram forte oposição à transmigração, essa carta contém intensas expressões figurativas. Vamos a um exemplo: "E agora, como nos querem fazer sair (oremosẽ) de valde desta terra que é nossa carne mesma (ko yvy ore ro'o tee)?" (São Nicolau, s. 39). De fato, eles ainda encontram uma resposta à sua pergunta retórica: o padre comissário somente quer privá-los de seu modo de ser "urbano", mandando irem para os matos, fato que empobrece a sua existência, "ainda que sejamos nós, também, cristãos". ${ }^{25}$

O ambiente de tensão gerado pela demarcação de limites foi propício para os índios gestarem ou registrarem expressões que refletem o seu pensamento político. Em duas cartas utilizam um verbo muito expressivo para qualificar a 
brutal mudança de atitude dos padres para com eles: mbote, composto do prefixo factitivo mbo- (fazer) e da raiz -te, cujos equivalentes em espanhol propostos pelos jesuítas seriam "error, desigualdade, diferencia, otro, desfigurado" ${ }^{26}$ Com isso mbote é fazer com que alguém seja desfigurado. O responsável por essa modificação é "el padre que se llama comisario", "es el que transforma (ombote) su comportamiento (de los jesuitas)" (São Nicolau, s. 55). "El sí ha hecho que nuestros padres sean otros de los que eran (ombote)." Não eram antes como são agora (Nicolas Ñeenguiru, s. 72).

Não é somente o teko (modo de ser) dos jesuítas que experimenta mudanças drásticas, a palavra do rei também, pois ele se havia comprometido a tratar bem os seus antepassados e a eles mesmos. Expressam assim em sua língua: "Como somente agora de repente querem mudar (ombote) sua palavra?" (Nicolas Ñeenguiru, s. 45). As cartas no seu conjunto revelam essa incompreensão profunda. Como pode mudar a vontade do rei? Se a vontade do rei não pode discrepar (joavy) da de Deus (Santo Angelo, s. 11), se a vontade do rei está mesclada (jehe'a) com a vontade de Deus (São João, s. 22), e se a justiça de Deus (tekojoja rerekua) é inalterável? (São Luis, s. 17 e São João, s. 43).

Afinal, como o rei pode mudar de decisão e com isso empobrecer-nos (momboriahu) e ainda "fazer que desapareçamos" (mokañy)? Recordam que os monarcas que antecederam a Fernando VI sempre haviam demonstrado por eles amor (ayhu), compaixão (poriahu vereko) e proteção (ñangareko), tendo tratado com atenção (porerekua), salvado (pyhyrõ) e ajudado (pytyvõ), manifestando gratidão pelos serviços prestados (angapyhy). Ademais, também foram fiéis e leais vassalos (voja) cristãos (karai), e sempre executaram ( $m b o-$ aje) e reverenciaram (mbojerovia) suas ordens. Nunca erraram (javy), incomodaram (ñemoangata) ou demonstram soberba (ñemboete) contra os espanhóis das cidades vizinhas, mesmo na época em que ainda viviam como infiéis. Enfim, são bons cristãos. Por esse motivo, não é correto entrar em guerra: "no es bien (ndikatúi) que nosotros todos christianos y pertenecientes â Dios peleemos unos contra otros" (São Luis, s. 6). As autoridades indígenas nas reduções ao que tudo indica conheciam os argumentos enunciados para sustentar a "guerra justa" contra os infiéis (especialmente as profanações e ataques aos estabelecimentos espanhóis).

Para tentar reverter a posição do governador Andonaegui e fundamentar a legitimidade de sua resistência, os indígenas mobilizam argumentos teológico-políticos de cuja construção e circulação, nos dois lados do Atlântico, os jesuítas participavam (Eisenberg, 2000). Em sua maioria, as cartas demonstram elevado grau de apropriação dos argumentos típicos da neoescolástica, como 
destacou Lía Quarleri em sua análise feita sobre as traduções ao espanhol (2009, p.195-199). A argumentação está embasada de maneira evidente nas teorias do direito natural, elaboradas a partir do século XIII por Tomás de Aquino: Deus dá razão a cada homem, para que possa conhecer a lei natural, eterna e divina. Ou seja: todo homem é capaz de conhecer o que é naturalmente justo. Por fim: pode julgar que o comportamento mundano do rei não se ajusta ao que a lei de Deus lhe prescreve. O rei está obrigado a amar os habitantes de suas terras como Deus ama o rei e os homens. Para um rei, amar seu povo é conservá-lo, protegê-lo contra eventuais abusos do próprio rei, evitar violências interiores e protegê-lo contra potências estrangeiras. De sua parte, os vassalos têm que amar ao rei e cuidar de suas terras (Heusch, 1993, p.134).

Esse argumento combina em três cartas com uma interpretação pactual da relação de vassalagem com o rei. Este havia dado sua palavra aos antepassados dos Guarani, comprometendo-se a tratá-los bem. Eles mesmos se deram ( $\left.m e^{\prime} \tilde{e}\right)$ ao rei como vassalos, e o escolheram (poravo) e colocaram suas terras - presente de Deus - sob sua proteção. Mas alguns matizes não foram contemplados em certas traduções, os quais expressam toda indignação frente ao que os Guarani consideram um engano, uma ruptura do seu pacto com o rei. Vejamos dois exemplos: “Acaso el santo rey Fernando Sexto engaña (mbotavy) a Dios nuestro Señor?, (por esto) nos dimos y ofrecimos la tierra donde estamos?" (São Miguel, s. 76). O rei havia sido enganado pelos portugueses que sabem mentir muito, porém "nosotros no nos dejamos engañar (ñembotavy) en un instante". ${ }^{27}$

A raiz - avy, muito presente em todos os textos dos Guarani, refere-se a algo desigual, errado. Traduzida de maneiras diversas, essa noção é recorrente nas cartas e indica o critério pelo qual eles estão avaliando as ações dos atores presentes no drama: os portugueses "pecam" muito (javy), são "mentirosos" (itavy), enganadores (ombotavy) do rei, que então engana (ombotavy) a Deus, tomando decisões contrárias aos seus interesses e aos de seus vassalos e territórios. A vontade do rei não deveria discrepar da de Deus (joavy), a qual não é mutável e não se equivoca (javy), nem sequer pode ser enganada (mbotavy).

A palavra e as obras do rei Fernando VI não são as mesmas (joavy) que as dos seus predecessores, ao passo que os Guarani não cometeram nenhum erro (javy), sendo sempre fiéis. "Pues no nos avia de engañar (mbotavy) diciendo esto (que el Rey nos agradece) el que nos trae las palabras del Rey” (São Miguel, s. 38). Então ameaçaram o governador: caso ele interpretasse mal as palavras do rei, seria castigado por seus erros (hembiavy). "Como pues o de 
que manera aora tu S.r Gov.or estas como que estas engañado (ñembotavy)?" (São Miguel, s. 54).

Não aceitavam a ordem real de transmigração, fundamentando sua oposição em uma linguagem política que recuperava o direito natural e a interpretação contratual do pacto monárquico, expressos pelos valores da arte verbal guarani.

\section{A título DE CONCLUSÃo}

O contato frequente com a cultura escrita nas reduções proporcionou aos Guarani uma experiência que lhes permitiu negociarem diretamente com a administração colonial, e mesmo entre eles, em um período de agitação política. A produção e circulação de correspondências entre indígenas nos permitem duas considerações. Primeiro, os indígenas fazem uso das missivas como maneira de comunicar às autoridades suas decisões, de acordo com as formalidades próprias à diplomacia; segundo, como já demonstrado, há o uso pessoal destinado à escrita pelos Guarani a partir de meados do século XVIII, que favoreceu a emancipação "escriturária" estimulando a redação de formas textuais pouco habituais na sociedade missioneira.

Enfim, foi pela troca de correspondência, da guerra de papel e de palavras, que os índios defenderam sua posição contrária ao tratado em curso, rompendo com décadas de "submissão" letrada e formularam argumentos justificando o seu direito de resistir a uma ordem real, ao mesmo tempo que se organizam e se preparam para uma guerra que avaliam como injusta. Entendiam seu pleito como um direito histórico, especialmente na questão da terra e do suor empenhado na sua defesa. Essa mobilização amparava-se nos usos de conceitos formulados com base nos valores monárquicos e nas teorias políticas ensinadas pelos jesuítas. As elites indígenas não desconsideravam as instituições missioneiras, muito pelo contrário, utilizavam-nas para legitimar suas demandas. Valiam-se para tanto dos fundamentos teológicos e jurídicos para justificar a sua oposição à ordem de transmigração. Seu autogoverno estava amparado em uma linguagem política que reportava ao pacto monárquico que os Guarani haviam estabelecido conjuntamente com os jesuítas no transcurso de um século e meio.

\section{BIBLIOGRAFIA}

ALMEIDA, Maria Regina Celestino de. Os índios na história do Brasil. Rio de Janeiro: Ed. FGV, 2010. 
AVELLANEDA, Mercedes. Orígenes de la alianza jesuita-guaraní y su consolidación en el siglo XVII. Memoria Americana - Cuadernos de Etnohistoria, Buenos Aires: Instituto de Ciencias Antropológicas, Facultad de Filosofia y Letras, UBA, n.8, p.173-202, 1999.

BOIDIN, Capucine. Pensar la modernidad/colonialidad en guaraní (XVI/XVIII). Cuadernos de antropologia social, Buenos Aires: UBA, n.44, p.7-25, $2016 \mathrm{a}$. Disponível em: http://revistascientificas.filo.uba.ar/index.php/CAS/article/ view/3577.

. Teko aguyjei, “derechos”, 'vida buena', un concepto político central de las proclamas y oficios del general Belgrano traducidos al guaraní. Ariadna histórica. Lenguajes, conceptos, metáforas, Universidad del País Vasco, Suplemento especial (1), p.25-51, 2016b. Disponível em: http://www.ehu.eus/ojs/index.php/Ariadna/ article/view/14278; Acesso em: 25 abr. 2017.

. Textos de la modernidad política en guaraní (1810-1813). Corpus. Archivos virtuales de la alteridad americana, v.4, n.2, 2014. Disponível em: https://corpusarchivos.revues.org/1322; Acesso em: 25 abr. 2017.

BOIDIN, Capucine; CHAMORRO, Graciela CHAMORRO; MÉRET, Géraldine. Introducción al dossier 'Fuentes en lenguas amerindias de América del Sur'. Corpus. Archivos virtuales de la alteridad americana, v.4, n.2, 2014. Disponível em: http://corpusarchivos.revues.org/1335; Acesso em: 25 abr. 2017.

BOUZA ÁLVAREZ, Fernando J. Del escribano a la biblioteca: la civilización escrita en la Alta Edad Média (siglos XV-XVII). Madrid: Síntesis, 1992.

CASTILLO GÓMEZ, Antonio. Entre la pluma y la pared: una historia social de la escrita en los Siglos de Oro. Madrid: Akal, 2006.

. (Org.) Escribir y leer en el siglo de Cervantes. Barcelona: Gedisa, 1999.

CERNO, Leonardo; OBERMEIER, Franz. Nuevos aportes de la lingüística para la investigación de documentos en guaraní de la época colonial, siglo 18. Folia histórica del Nordeste, Resistencia, n.21, p.33-56, 2013.

CORTESÃO, Jaime Zuzarte. O Tratado de Madrid. Brasília: Senado Federal, ed. fac-similar. 2v., 2001. (Coleção Memória Brasileira).

COUCHONNAL, Ana; WILDE, Guillermo. De la política de la lengua a la lengua de la política. Cartas guaraníes en la transición de la colonia a la era independiente. Corpus. Archivos virtuales de la Alteridad Amerindia, v.4, n.1, 2014. Disponível em: http://corpusarchivos.revues.org/774; Acesso em: 25 abr. 2017.

DURSTON, Alan. Indigenous languages and the historiography on Latin America. Storia della storiografia, v.67, n.1, p.56-66, 2015.

EISENBERG, José. As missões jesuíticas e o pensamento político moderno: encontros culturais, aventuras teóricas. Belo Horizonte: Ed. UFMG, 2000.

GANSON, Barbara. The Guarani under spanish rule in the rio de la Plata. Stanford: Stanford University Press, 2003. 
GARCIA, Elisa Frühauf. As diversas formas de ser índio: políticas indígenas e políticas indigenistas no extremo sul da América Portuguesa. Rio de Janeiro: Arquivo Nacional, 2009.

GARRETT, David T. Sombras del Império: la nobleza indígena del Cuzco, 1750-1825. Lima: IEP, 2009.

GUILHAUMOU, Jacques. De l'histoire des concepts à l'histoire linguistique des usages conceptuels. Genèses, v.38, n.1, p.105-118, 2000.

HERZOG, Tamar. Frontiers of Possession: Spain and Portugal in Europe and the Americas. Cambridge, Mass.: Harvard University Press, 2015.

KOSELLECK, Reinhart. Futuro passado: contribuição à semântica dos tempos históricos. Rio de Janeiro: Contraponto, 2006.

MANUSCRITOS da Coleção de Angelis. Tomo VII: do Tratado de Madri à conquista dos Sete Povos (1750-1802). Introd., notas e sumário: Jaime Cortesão. Rio de Janeiro: Biblioteca Nacional, 1969.

MATEOS, Francisco. La guerra guaranítica y las misiones del Paraguay: Primera Campaña (1753-1754). Missionalia Hispânica, Madrid, v.8, n.23, p.241-316, 1951. MELIÀ, Bartomeu. Escritos guaraníes como fuentes documentales de la historia Paraguaya. História Unisinos, São Leopoldo, v.9, n.1, p.5-18, 2005.

. El Guaraní conquistado y reducido: ensayos de etnohistoria. 4.ed. Asunción: Cepag, 1997.

. La lengua guaraní en el Paraguay colonial: que contiene la creación de un lenguaje cristiano en las Reducciones de los Guaraníes en el Paraguay. Asunción: Cepag, 2003.

MONTEIRO, John M. Tupis, tapuias e historiadores: estudos de história indígena e do indigenismo. Tese (Livre Docência em Antropologia) - Universidade Estadual de Campinas (Unicamp). Campinas, 2001.

MONTOYA, Antonio Ruiz de. Tesoro de la lengua guaraní (Madrid, Iuan Sanchez, 1639). Reeditada e transliterada por Bartomeu Melià s.j. y Friedl Gründberg. Asunción: Cepag, 2011.

NEUMANN, Eduardo. Escribiendo en la frontera del Paraguay: prácticas de la escritura guaraní durante la demarcación de límites (siglo XVIII). Cultura Escrita \& Sociedad, Gijón: Ed. Trea, n.7, p.159-190, 2008.

A lança e as cartas: escrita indígena e conflito nas reduções do Paraguai Século XVIII. História Unisinos, São Leopoldo, v.11, n.2, p.160-172, 2007.

. Letra de índios: cultura escrita, comunicação e memória indígena nas Reduções do Paraguai. São Bernardo do Campo: Nhanduti, 2015.

. Práticas letradas Guarani: produção e uso da escrita indígena (séculos XVII e XVIII). Tese (Doutorado) - IFCS, Universidade Federal do Rio de Janeiro (UFRJ). Rio de Janeiro, 2005.

NEUMANN, Eduardo; WILDE, G. Escritura, poder y memoria en las reducciones jesuíticas del Paraguay: trayectorias de líderes indígenas en tiempos de transición. 
Colonial Latin American Historical Review, Albuquerque, N.M., v.2, n.3, p.353-380, 2014.

OWENSBY, Brian. Pacto entre rey lejano y súbditos indígenas. Justicia, legalidad y policía en Nueva España, siglo XVII. Historia mexicana, México, v.61, n.1, p.59-106, 2011. Disponível em: http://www.redalyc.org/articulo.oa?id=60022589002; Acesso em: 25 abr. 2017.

PALTI, Elías Jose. The "Theoretical Revolution" in Intellectual History: From the History of Political Ideas to the History of Political Languages. History and Theory, v.53, n.3, p.387-405, 2014.

POCOCK, John Greville Agard. Pensamiento político e historia: ensayos sobre teoría y método. Madrid: Akal, 2011.

QUARLERI, Lía. Rebelión y guerra en las fronteras del Plata: guaraníes, jesuitas e imperios coloniales. Buenos Aires: Fondo de Cultura Económica, 2009.

ROSANVALLON, Pierre. Pour une histoire conceptuelle du politique (Note de Travail). Revue de synthèse, v.107, n.1-2, p.93-105, 1986.

SANTOS, Maria Cristina dos; FELIPPE, Guilherme Galhegos. Protagonismo como substantivo na História indígena. In: . (Org.) Protagonismo ameríndio de ontem e hoje. Jundiaí: Paco, 2016. p.13-52.

SEBASTIÁN, Javier Fernández (Ed.) Diccionario político y social del mundo iberoamericano. Madrid: Sociedad Estatal de Conmemoraciones Culturales; Centro de Estudios Políticos y Constitucionales; Fundación Carolina, 2009.

SKINNER, Quentin. As fundações do pensamento político moderno. São Paulo: Companhia das Letras, 1996.

THUN, Harald; CERNO, Leonardo; OBERMEIER, Franz. El Proyecto Kuatia Ymaguare (PEKY) - 'Libros del pasado'. Estudios Históricos, v.VII, n.14, s.n.p., 2015a.

THUN, Harald; CERNO, Leonardo; OBERMEIER, Franz (Ed.) Guarinihape tecocue - lo que pasó en la guerra (1704-1705): Memoria anónima en guaraní... (Edición crítica). Kiel: Westensee Verlag, 2015b. (Fontes Americanae).

WILDE, Guillermo. Antropología histórica del liderazgo Guaraní misionero (1750/1850). Tese (Doutorado) - Facultad de Filosofía y Letras, Universidad de Buenos Aires. Buenos Aires, 2003.

Religion y poder en las misiones de guaraníes. Buenos Aires: SB, 2009.

\section{NOTAS}

${ }^{1}$ Para uma discussão que destaca o lugar dos índios na História, ver MONTEIRO, 2001; ALMEIDA, 2010; para uma reflexão teórica atualizada a respeito do uso do conceito de "protagonismo" ameríndio, ver SANTOS; FELIPPE, 2016, p.13-52. Para um balanço da historiografia sobre as línguas indígenas e a questão do letramento indígena, ver DURSTON, 2015. 
${ }^{2}$ GANSON, 2003; WILDE, 2003 e 2009; NEUMANN, 2005, 2008 e 2015; QUARLERI, 2009; COUCHONNAL; WILDE, 2014. Quanto à tradução e edição dos textos em guarani, MELIÀ, 2003 e 2005; CERNO; OBERMEIER, 2013; THUN; CERNO; OBERMEIER, 2015a e 2015b; BOIDIN, 2014 e 2016a; ADOUE; ORANTIN; BOIDIN, 2014.

${ }^{3}$ No momento, desenvolvemos uma história de discursos e pensamentos políticos em línguas ameríndias, sob a égide do grupo denominado Iberconceitos. Ver, especialmente: SEBASTIÁN, 2009. Esse grupo procura integrar aportes de distintas escolas, com ênfase nas propostas de Reinhart Koselleck. Para uma história das ideias políticas de linhagem francesa, ver: ROSANVALLON, 1986; GUILHAUMOU, 2000; para a chamada Escola de Cambridge, que analisa ideias e linguagens políticas em seus contextos históricos, ver: SKINNER, 1996; POCOCK, 2011; e para uma história dos conceitos de vertente alemã: KOSELLECK, 2006. Uma aproximação a essa discussão em: PALTI, 2014, p.387-405.

${ }^{4}$ A respeito dos antecedentes e circunstâncias desse tratado, ver: CORTESÃO, 2001. Para uma leitura atualizada dessas negociações travadas nas fronteiras americanas, que envolveram uma série de reivindicações pela ocupação desses territórios, ver: HERZOG, 2015.

${ }^{5}$ Durante o período de demarcação de limites na América meridional as reações indígenas foram diversas, e nem todos manifestaram oposição às novas medidas. Sabemos que uma parcela da população foi transmigrada para outras reduções, localizadas na margem ocidental do rio Uruguai, e que outras famílias aceitaram acompanhar o general português Gomes Freire de Andrade, passando a ocupar terras da América lusitana, convertendo-se em súditos do Monarca português (GARCIA, 2009).

${ }^{6}$ As fontes manuscritas sobre o conflito nas reduções apresentam grande variedade, seja na forma de correspondência administrativa, de cartas escritas por jesuítas ou informes variados entre as autoridades. Os documentos localizados na península Ibérica são procedentes, em sua maioria, de arquivos espanhóis, e os sul-americanos estão depositados em instituições argentinas. No Arquivo Histórico Nacional (AHN/Madri), e no Arquivo General de Simancas (AGS/Valladolid), estão depositados alguns manuscritos redigidos pelos guaranis, ou cópias de documentos indígenas traduzidos ao espanhol. A documentação indígena localizada na América corresponde principalmente aos manuscritos guardados no Arquivo General de la Nación (AGN/Buenos Aires), além de outros documentos depositados no Museu Mitre (MM/Buenos Aires).

${ }^{7}$ Para uma aproximação à questão da escrita em línguas indígenas e à problemática das traduções, ver o Projeto Línguas Gerais da América do Sul (Langas), coordenado por Capucine Boidin e Cesar Itier. Disponível em: www.langas.cnrs.fr. Ver também: BOIDIN; CHAMORRO; MÉRET, 2014.

${ }^{8}$ Refiro-me aos incidentes registrados em Santa Tecla, na estância de São Miguel, em fevereiro de 1753 (AGS: Secretaria de Estado, Legajo 7378, Doc. 89: Copia de la declaración de lo acaecido con los Indios Tapes en la oposición que hicieron en no permitir el paso a la primera Partida para la Demarcación de la Línea divisoria de esta America Meridional y las diligencias que se practicaran para conseguir el fin de que se Combiniesen con las órdenes del Rey). 
${ }^{9}$ Para uma breve descrição da trajetória de alguns indígenas nas reduções durante a demarcação de limites e no período posterior à expulsão dos jesuítas, ver: NEUMANN, 2007 e 2015, NEUMANN; WILDE, 2014.

${ }^{10}$ AGS: Secretaria de Estado. Legajo 7378. Doc. 38 (Copia): Carta de Lorenzo Balda al padre comisario Luis Altamirano. San Miguel y enero 18 de 1753.

${ }^{11}$ AHN: Clero-Jesuitas. Legajo, Caja 1, Doc. 7. Breve resumen del Tratado entre España y Portugal tocante a varias Provincias de la América Meridional, p.20.

${ }^{12}$ Uma relação dos maus tratos aos corregedores é a carta de Luis Charlet, de 27 de março de 1753. "A la vuelta flecharan al Corregidor le abrieron la cabeza, y les molieron a palos ... A el de Santo Angel según me escrivio el padre Piza lo quisieron matar de pesadumbre se murió. A él de San Miguel por poco no lo mataron, y estuvo sacramentado. A el de San Nicolas lo quisieron matar, y se huyo a la Concepción. A el corregedor de aquí, y de San Miguel nos lo hicieron apear estando el Pueblo en tumultos..." (AHN: Clero-Jesuitas. Legajo 120, Caja 1, Doc. 7. p.20).

${ }^{13}$ Real Academia de la História/Madri (RAH): Fondo manuscrito. Colección Mutis. Carta de Charlet a Altamirano. San Juan y noviembre 8 de 1752.

${ }^{14}$ AHN: Clero-Jesuitas. Legajo 120, Caja 1, Doc. 7. p.26.

${ }^{15}$ AGS: Secretaria de Estado, Legajo 7378. Doc. 37 (Copia).

${ }^{16}$ RAH: Sobre el Tratado con Portugal en 1750. P. Manuel Quirino. Sig: 9/2279, nota 51.

${ }^{17}$ AGS: Secretaria de Estado. Legajo 7433, Doc. 278 (carta em guarani, anexa ao processo). Até o presente momento esta é a carta mais antiga escrita e assinada em guarani, por autoridades indígenas das reduções, localizada nos arquivos. Ela evidencia o domínio dos protocolos epistolares típicos à época: menciona o destinatário (Corregidor Pazq.l Tirapare.), começa com uma formulação cristã (Alabado sea el Santísimo sacramento), apresenta uma saudação na abertura (Que Dios te guarde, Capitán, y que nuestros hijos también vuelvan a vivir bien...) indica sua finalização (Pero esto no más te escribo un poco, corregidor) e concluí indicando a data e local "Desde San Miguel y Febrero 20 de 1753" além de estar assinada ao final: "El teniente que te quiere Alejandro Mbaruari".

${ }^{18}$ AGS: Secretaria de Estado. Legajo 7378, Doc. 91: Copia de una carta que entregaron los Indios al Comisario de la primera Partida traducida de su Idioma Guarany al Castellano.

${ }^{19}$ Para uma aproximação ao papel desempenhado pela cultura escrita na Espanha da Idade Moderna, ver: BOUZA, 1992; CASTILLO, 1999 e 2006.

${ }^{20}$ AGS: Secretaria de Estado, Legajo 7378, Doc. 103.

${ }^{21}$ AHN: Clero-Jesuitas. Legajo 120, Caja 1, Doc. 31, 32, 33, 34, 36, 37, 38.

${ }^{22}$ As cartas em guarani citadas neste artigo foram publicadas na base de dados www.langas. cnrs.fr em julho de 2016. As transcrições paleográficas do guarani e do espanhol foram realizadas por Cecilia Adoue, e as transliterações à grafia moderna e divisão em sessão das versões em guarani e sua correspondência com as traduções ao espanhol ficaram aos cuidados de Capucine Boidin. As fontes localizadas contabilizam 248 documentos escritos em guarani pelos próprios índios das reduções entre 1752 e 1832. Até o presente momento o 
projeto Langas analisou 178 cópias desses documentos. Em torno de $60 \%$ destes foram localizados sem tradução ao espanhol. A equipe do projeto Langas se dedica a editar esses documentos. Para a guerra guaranítica foram localizados 69 documentos, sendo $11 \mathrm{em}$ idioma guarani. Conforme o trabalho de arquivo avance, esse corpus poderá ser ampliado.

${ }^{23}$ Em meados do século XVIII a elite indígena nos Andes também utilizou a escrita para questionar as medidas modernizantes, pois avaliavam como mais adequado apresentar suas insatisfações e desafiar a autoridade real nos tribunais. Ver: GARRETT, 2009. Para Nueva España, ver: OWENSBY, 2011.

24 “ndaha'evéi oréve jepe peteĩ ñe'ẽ hesegua chupe imosẽ haguãma”. Literalmente: "Ya no existe para nosotros ni una sola palabra a propósito de esto para hacerles salir" (Carta de Nicolas Ñeenguiru, s. 30). Doravante nos referiremos apenas às versões em guarani transliteradas para a grafia moderna e às versões em espanhol paleografadas que constam na base de dados online (www.langas.cnrs.fr), indicando o número da seção na qual se encontra a frase ou a palavra citada.

25 “E quer tirar-nos (mo-sẽ) nosso modo de ser. Ao mato, desde nosso Povo. Ao campo, longe quer mandar-nos. Não, isto, em verdade não o quer Deus. E nós também somos cristãos. Só querem empobrecernos (momboriahu). Só querem nos perder parece (mokañy) Que classe de Cura é este?” (Carta de São Nicolau, s. 39).

${ }^{26}$ MONTOYA (1639), 2011, p.540.

${ }^{27}$ A citação original da primeira carta é "Ma Ombotavy tepipo Rey Fernando Sexto marangatu Tupã Nande Jára upe orekuave'ẽ haguéra, yvy ore rekoha jepe, kuave’ẽ haguéra”, e foi traduzida de maneira elegante por "Pues qe el avernos nros dado â D.s y aver ofrecido la tierra donde estamos hade servir paraqe el S.to Rey Fern.do sexto sea malo? por ventura? Traduzem como ‘ombotavy Tupã upe' (engañar a Dios) por 'ser malo’” (São Miguel, s. 76). A segunda "Portugues niko itavy jeahose retei va'e, aipo rehe ndoroñembotavý jesapy’atei, japura vai kuaapa rete nanga eguĩ Portugues", que é, literalmente "Los Portugueses, por cierto, que son errados en exceso, y por esto nosotros (exclusivo) no nos dejamos engañar en un instante, ellos saben mentir mucho, esos Portugueses", mas esta foi traduzida por "Ciertamente esta es cosa de los Portugueses, que son muy malos, y saben mentir mucho" (São João, 1752, s. 5).

Artigo recebido em $1^{\circ}$ de maio de 2017. Aprovado em 14 de julho de 2017. 